\title{
Effects of Organizational Learning Culture and Developmental Feedback on Engineers' Career Satisfaction in the Manufacturing Organizations in Malaysia
}

\author{
[Johnny Ding Dung Ngie, Nasina Mat Desa \& Muhammad Hasmi Abu Hassan Asaari]
}

\begin{abstract}
The purpose of this paper is to test the hypotheses that relations between organizational learning culture, developmental feedback and career satisfaction in the manufacturing organizations. A sample of 155 engineers was drawn from two major manufacturing organizations located in the Northern Malaysia. Participation in the research was voluntary and data were gathered by means of a survey questionnaire. Multiple regression results provided support for the direct impact of organizational learning culture and developmental feedback on the engineer's career satisfaction. Key implications of the survey findings both of the theory and practice are discussed, potential limitations are specified, and directions for future research are suggested.
\end{abstract}

Keywords - organizational learning culture, developmental feedback, career satisfaction, engineers, manufacturing

\section{Introduction}

According to Malaysian Employers Federation (MEF), in the manufacturing sector, the electrical and electronics section having the second highest turnover rate of 23.04 percent per annum [1]. The interview with a few of the human resource managers of this manufacturing organizations in Bayan Lepas Free Trade Zone, Northern Region of Malaysia revealed that career satisfaction is one of the major factors that influence engineers' turnover [1]. Therefore, it is crucial for us to determine the predictors of career satisfaction among engineers in the Bayan Lepas, Free Trade Zone area, which is the largest industrial manufacturing zone in the Northern Region of Malaysia.

Career satisfaction is assessed as a subjective career success which defined by individual's satisfaction with their career accomplishments. Amongst the famous predictors of career satisfaction are pay and promotion [2]. Pay and promotion are always regarded as a part of the organizational factor. We are interested on the different factor, that are called contextual factors such as

Jonny Ding Dung Ngie

Wawasan Open University

Penang, Malaysia

Nasina Mat Desa

Universiti Sains Malaysia

Penang, Malaysia

Muhammad Hasmi Abu Hassan Asaari

Universiti Sains Malaysia

Penang, Malaysia organizational learning culture and developmental feedback.

Organizational learning culture is defined as "an organization skilled at creating, acquiring, and transferring knowledge, and at modifying its behavior to reflect new knowledge and insights" [3]. Developmental feedback is defined as the extent to which supervisors provide employees with useful information that enables the employees to learn, develop, and improve on the job [4]. Supervisors will be able to improve the employee performance by engaging in this way.

According to [5], organizational learning culture and developmental feedback would significantly influence career satisfaction. As there are a limited number of research in related to manufacturing and engineers, the purpose of this paper is to test the hypotheses that relations between organizational learning culture, developmental feedback and career satisfaction in the manufacturing organizations.

\section{Literature Review}

\section{A. Organizational Learning Culture}

According to [6] and [7], organizational learning culture is composed of both the people level (i.e. continuous learning, dialogue and inquiry, team learning, and collaboration) and the structural level (i.e. embedded system, system connection, empowerment and structural leadership).

Organizational learning culture is an influential contextual characteristic to enhance positive outcomes in the HRD aspect [8] [9]. Marsick \& Watkins 2003). According to [8], organizational learning culture will enhance the employees' level of career satisfaction. Employee participative decision making [10], employee empowerment [11], and leadership behaviors inspiring teamwork [12] had a significant influence on career satisfaction.

\section{B. Developmental Feedback}

Developmental feedback is defined as supervisor provides valuable messages to employees and empower the employees to develop, learn, and make improvements on the job [4]. Organization engaging in this practice, which supervisors actively provide employees with behavioral feedback that influence employees to improve their performance in the absence of pressure for a particular 
outcome. The behavioral feedback practices with the objective to boost intrinsic motivation [13] and strengthen the interest desire in the task itself with an orientation toward learning and advancement.

Some studies suggested that positive or developmental feedback has generate positive energy on career satisfaction. According to [14], employee satisfaction with performance reviews come with superiority of performance feedback combined with goal setting over performance feedback session. Besides, [15] discovered positive feedback from supervisors enables employees to learn positive ways of doing things, behaviors reinforcement, competency improvement, and enhances performance satisfaction in their job function. Thus, with efficient developmental feedback expected to increase career satisfaction of employees.

\section{Career Satisfaction}

[16] found that career satisfaction is the overall corporate attachment \& its feelings of an individual, through out his/her career. It is a measure of satisfaction or dissatisfaction of an individual about his/her career. It is a perception that how an individual feels about his current job. According to [17], when someone is satisfies with his/her job and things that his/her career is secure and a safe through this job than he would be more satisfied.

[18] suggested that one-way organizations may meet the challenge to support their employees in developing their own careers and increase their career satisfaction. This approach recommend organizations perform a new supportive, rather than directive role in empowering their employees' career success.

According to [19], career satisfaction is the intrinsic and extrinsic aspects of the personal satisfaction obtain from their careers, including salary, advancement, and developmental opportunities. It has been perceived as an integral factor in the career success and as an important criterion for an individual's career value as a whole [20]. [21] [22] [23] found that career satisfaction assess the extent of individuals believe their career progress is consistent with their own goals, values and preferences.

Career satisfaction and career success were interchangeably used in many career researches. [21] defined career success as a positive psychological or workrelated outcomes that a person gained as a result of work experiences. Previous research has viewed career being passive for individual and influenced by situational factors [24]. Whatsoever, some recent studies thought that personality through certain behaviors would influence the environment. [23] noticed that career success seem to be cumulative outcome of behaviors over a long-time period which personality is likely playing a role.

\section{Theoretical Framework and Hypotheses Development}

According to [25], organizational learning culture and developmental feedback are significantly correlated with career satisfaction. Thus, Figure 1 depicts the theoretical framework.

Figure 1: Theoretical Framework

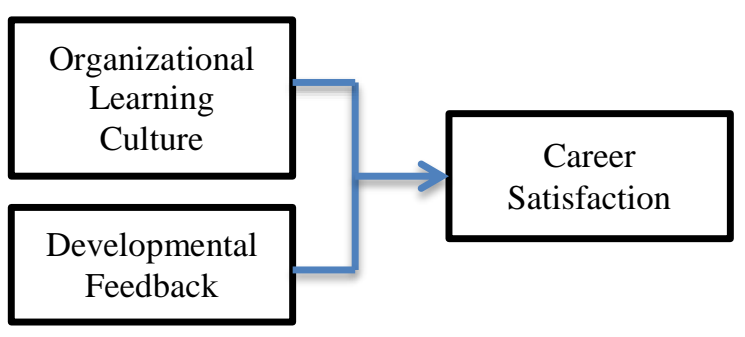

\section{A. Organizational learning culture and Career satisfaction}

[32] expected organizational support for career development (OSCD) introduces the necessary programs, processes, and assistance to support and strengthen their employees' career success. This includes formal strategies (career planning, training and assessment centers) and informal support such as coaching and mentoring opportunities [33] [34]. [25] disclosed in their study of Korean employees that organizational learning culture has significant correlation with career satisfaction. Thus, it is more likely that organizational learning culture will affect career satisfaction:

$\mathrm{H}_{1}$ : Perceived organizational learning culture will be positively related to employee's career satisfaction

\section{B. Developmental Feedback and Career Satisfaction}

The previous studies found that the developmental or positive feedback has a positive correlation on career satisfaction. [14] found that there is advantage of doing employees' performance feedback and goal setting concurrently instead of performance feedback alone with respect to their satisfaction with performance reviews. Additionally, supervisors' positive feedback would cultivate employees to learn effective way of doing things, reinforces positive behaviors, enhances their competence, and improves performance satisfaction in the workplace. Therefore, with the expectation of regular developmental feedback will cultivate better career satisfaction:

$\mathrm{H}_{2}$ : Perceived developmental feedback will be positively related to employee's career satisfaction

\section{Iv. Methodology}

Below are the methodology used in this study. 


\section{A. Population and Respondents}

The population and respondents of this study were engineers whom are working in the two manufacturing organizations in Bayan Lepas Free Trade Zone, Penang, the Northern Region of Malaysia. There were 255 questionnaires randomly distributed to the engineers.

\section{B. Measures}

The organizational learning culture questionnaire was developed by [9] and further validated by [6]. This study adopted the seven items from Yang et al. (2004) shortened version of the organizational learning culture questionnaire. The Cronbach's alpha coefficient was 0.81. All these measures were assessed using a five-point Likert-type scale ranging (1) "strongly disagree to (5) "strongly agree".

Developmental feedback was measured with three-item scales developed and validated by [4]. The reliability coefficient of the five items was 0.82 in this study. All these measures were assessed using a five-point Likert-type scale ranging (1) "strongly disagree to (5) "strongly agree".

A five items developed and validated by [19] was used for this study to measure career satisfaction. The Cronbach's alpha coefficient was 0.81 . The survey questionnaire measured with a five-point Likert scale ranging (1) "strongly disagree to (5) "strongly agree".

\section{v. Results}

A total of 159 questionnaires were returned with the response rate of $62.1 \%$. However, there was 4 questionnaires unusable due to incorrectly or incompletely responses. As a result, only 155 questionnaires were usable and given the final response rate of $60.5 \%$. The respondents of this survey consisted of $74.2 \%$ male engineers and $25.8 \%$ female engineers.

Majority of the respondents are below 40 years. Most of the respondent are holding a bachelor degree qualification $(38.1 \%)$ and holding a senior engineer post $(50.3 \%)$. The respondents working tenure in the current post is two to six years and majority of the respondent earned Ringgit Malaysia of five thousand per month.

\section{A. Correlations Analysis}

Correlations analysis was done on the organizational learning culture and developmental feedback with career satisfaction. The relationship between organizational learning culture and developmental feedback with career satisfaction were investigated using correlation coefficient. Preliminary analyses were performed to measure no violation of the assumptions of normality, linearity and homoscedasticity. Based on the correlation analysis results below, career satisfaction has a significant positive relationship with organizational learning culture $(r=0.41, p<$ $.01)$ and developmental feedback $(r=0.37, p<0.01)$. Overall, there were strong correlation $(\mathrm{p}<0.01$ and $\mathrm{p}<0.05)$ between variables.

\section{B. Multiple Regressions}

Multiple regression analysis was employed to predict the impact of the organizational learning culture and developmental feedback on career satisfaction. The results of multiple regression analysis, $\mathrm{R}^{2}$ is 0.22 has indicated that organizational learning culture and developmental feedback affected $22 \%$ of career satisfaction among the engineers.

Based on the multiple regression analysis, organizational learning culture $(\beta=0.30, p<0.01)$ has a significant effect on career satisfaction. This result concludes that organizational learning culture is positively related to career satisfaction. Thus, hypothesis one (H1) is supported.

Developmental feedback $(\beta=0.24, p<0.01)$ was significantly related to career satisfaction. Thus, developmental feedback is a significant predictor for the career satisfaction. Hypothesis two (H2) is supported.

\section{vi. Discussion \& Conclusion}

This study has revealed that two contextual factors; organizational learning culture and developmental feedback, were predictors for career satisfaction of engineers. It also stamps the importance of cultivating learning cultures as to providing feedback to them. It can be interpreted as a means for managing the relationships between organizational learning culture and developmental feedback through the connections between organizational purposes to cultivate individual improvement.

\section{A. The relationship between organizational culture and career satisfaction}

In this study, organizational learning culture was significantly related to career satisfaction, replicating previous researches [8] [25]. This result is related to characteristics of organization learning culture that provides continuous learning, dialogue and inquiry, team learning, embedded system, empowerment, collaboration and strategic leadership [9]. [26] advocated that organizational learning culture depends on the acquisition of information, the interpretation of information and the formation of organizational knowledge. Example of learning cultures are creating continuous learning opportunities; promote inquiry and dialogue; encourage collaboration and team learning; establish systems to capture and share learning; empower people to have a collective vision; connect the organization to the environment; and use leaders who model and support learning at the individual, team, and organization levels [7].

Findings from this study also indicated that the 59\% of engineers who are working in this manufacturing organizations belong to Gen $\mathrm{Y}$. Gen $\mathrm{Y}$ defines organizational learning culture as an environment where they can constantly learn and be challenged [27]. Thus, organizations must provide that learning platform for their engineers. Furthermore, Gen Y also has the desire to make crucial decisions of an organization soon after entering the organization; they do not desire to wait for important duties 
[28]. Scholars note that Generation Y expects to be valued by their employers as the key assets of the organization and that their input will be taken into full account and acted on by their employers [27] [28] [29]. Organizations must find ways to win the heart of this new generation, Generation Y.

\section{B. The relationship between developmental feedback and career satisfaction}

The finding has revealed that developmental feedback was significantly related to career satisfaction, replicating previous researches [14] [15]. This is a surprising finding because [25] did not support this hypothesis in Korea. This is probably due to the organizational learning culture that both manufacturer, are actively practicing, which are the one-to-one feedback session on a weekly basis and during the engineer's performance appraisal.

This study also recognized the critical role of managers in organizational learning culture and developmental feedback. It highlights the importance of organizational learning culture to the engineers. Managers should encourage subordinates to increase their career satisfaction through establishing productive learning culture and providing positive feedback [25]. According to [14], it is important that performance feedback session coupled with goal setting compare to performance feedback alone with respect to employee satisfaction with performance reviews.

This study has found that Gen $\mathrm{Y}$ is continuously looking for feedback and advice from their superior, it was most likely a result of their strong ties to and constant feedback from their parents [30] [28]. On the job, Gen Y expects frequent direction from superiors regarding their performance. They recognize the role knowledge plays in career advancement and look for opportunities to learn from their superiors and older generations [28]. Additionally, Generation $\mathrm{Y}$ views failure as a motivator and not a deterrent. Thus, they view failure as an opportunity to improve job performance [29]. [15] also found that positive feedback from supervisors enables employees to learn better ways of doing things, reinforces appropriate behaviors, improves their overall competence, and achieve career satisfaction in their working field.

Overall, this research has found that contextual characteristics such as organizational learning culture and developmental feedback have had significant impacts on employees' career satisfaction. Practically, managers and HRD/OD professionals should provide support on employee career satisfaction by developing, improving, and delivering the relevant practices, ensuring that the climate and HR practices are such that career satisfaction can be realized. One of the practical ways is to help managers adopting new roles as coaches and learning facilitators. For example; HR Department could design and provide relevant training programs to their managers to embark themselves as coaches and facilitators to their subordinates. Moreover, as an organization reflected themselves as a team, the role of a manager has changed from a traditional hierarchical directive to being a supportive and non-controlling figure. Thus, coaching and mentoring have became as a significant employee development strategy. Explicitly, managerial coaching or manager-as-coach has became nowadays crucial management strategy to increase employees career satisfaction in many organizations [31].

In conclusion, in the Malaysian context, this study provides useful information to researchers who conduct similar studies in different cultural backgrounds. It is also contributes to recognizing the critical role of managers in organizational learning culture and developmental feedback. Managers could encourage subordinates to increase career satisfaction through establishing productive learning culture and providing positive feedback. For example, organizations policy makers should encourage continuous learning opportunity, establish system to capture and share learning, and managers should provide employees with behaviorally relevant information that leads employees to improve their performance in the future in the absence of pressure for a particular outcome.

\section{Acknowledgment}

The author would like to thank Universiti Sains Malaysia for the funding under Short Term Grant.

\section{References}

[1] Wong, K. 2012. Malaysia Average Turnover Rate for Executive - GEC Business Review, http://geconsult.blogspot.com/2012/03/malaysiaaverage-turnover-rate-for.html (accessed February 2, 2013)

[2] Judge, T.A., Cable, D.M., Boudreau, J.W. and Bretz, R.D. 1995. An empirical investigation of the predictors of executive career success. Personnel Psychology, 48(3): 485-519.

[3] Garvin, D. A. 1993. Building a learning organization. Harvard Business Review, 71: 78-91.

[4] Zhou, J. 2003. When the presence of creative co-workers is related to creativity: role of supervisor close monitoring, developmental feedback, and creative personality. Journal of Applied Psychology, 88(3): 413-22.

[5] Farr, J.L., Hofmann, D.A. and Ringenbach, K.L. 1993. Goal orientation and action control theory: implications for industrial and organizational psychology, in Cooper, C.L. and Robertson, I.T. (Eds), International Review of Industrial and Organizational Psychology , 193-232. Wiley, New York, NY

[6] Yang, B., Watkins, K., \& Marsick, V. 2004. The construct of the learning organization: Dimensions, measurement, and validation. Human Resource Development Quarterly, 15: 31-55.

[7] Watkins, K. E., \& Marsick, V. J. 1997. Dimensions of the learning organization. Warwick, RI: Partners for the Learning Organization.

[8] Egan, T. M., Yang, B., \& Bartlett, K. R. 2004. The effects of organizational learning culture and job satisfaction on motivation to transfer learning and turnover intention. Human Resource Development Quarterly, 15(3): 279-301.

[9] Marsick, V. J., \& Watkins, K. E. 2003. Demonstrating the value of an organization's learning culture: The dimensions of the learning organization questionnaire. Advances in Developing Human Resources, 5: $132-151$.

[10] Daniels, K. and Bailey, A.J. 1999. Strategy development processes and participation in decision-making: predictors of role stressors and job satisfaction. Journal of Applied Management Studies, 8(1): 27-42.

[11] Johnson, J.J. and Mcintye, C.L. 1998. Organizational culture and climate correlates of job satisfaction. Psychological Reports, 82(1): 843-50.

[12] Gaertner, S. 2000. Structural determinants of job satisfaction and organizational commitment in turnover models. Human Resource Management Review, 9(4): 479-493.

[13] Deci, E.L. and Ryan, R.M. 1985. Intrinsic Motivation and Selfdetermination in Human Behavior . Plenum Press, New York. 
[14] Nemeroff, W.F. and Cosentino, J. 1979. Utilizing feedback and goal setting to increase performance appraisal interviewer skills of managers. Journal of Applied Psychology, 22(3): 566-576

[15] Jaworski, B.J. and Kohl, A.K. 1991. Supervisory feedback: alternative types and their impact on salespeople's performance and satisfaction. Journal of Marketing Research, 28(2): 190-201.

[16] John, W. L., Robert, P. S., Lucy, W. G. \& Adam W. D. 2008 Personality traits and career satisfaction of human resource professionals. Human Resource Development International, 11(4): 351 $-366$

[17] Steve, D. \& Catherine, S. 1998. A three domain model of teacher and school executive career satisfaction. Journal of Educational Administration, 36(4): 362-378.

[18] Baruch, Y. 2006. Career development in organizations and beyond: balancing traditional and contemporary viewpoints. Human Resource Management Review, 16: 125-38.

[19] Greenhaus JH, Parasuraman S, Wormley WM. 1990. Effects of race on organizational experiences, job performance evaluations, and career outcomes. Academy of Management Journal, 33: 64-86.

[20] Gattiker, U. E., \& Larwood, L. 1988. Predictors for managers' career mobility, success, and satisfaction. Human Relations, 41: 568-591.

[21] Erdogan, B., Kraimer, M.L. and Liden, R.C. 2004. Work value congruence and intrinsic career success: the compensatory roles of leader-member exchange and perceived organizational support. Personnel Psychology, 57(2): 305-332

[22] Heslin, P.A. 2003. Self and other-referent criteria of career success. Journal of Career Assessment, 11(3): 262-86.

[23] Seibert, S.E., Crant, J.M. and Kraimer, M.L. 1999. Proactive personality and career success. Journal of Applied Psychology, 84(3): 416-27.

[24] Bell, N.E. and Staw, B.M. 1989. People as sculptors versus sculpture: the role of personality and personal control in organizations, in Arthur, M.B., Hall, D.T. and Lawrence, B.S. (Eds), The Handbook of Career Theory, 232-251. Cambridge University Press, Cambridge.

[25] Joo, B. \& Park, S. 2010. Career satisfaction, organizational commitment, and turnover intention: The effects of goal orientation, organizational learning culture and developmental feedback. Leadership \& Organization Development Journal, 31(6): 482 - 500.

[26] Hurst, J.L. and Good, L.K. 2009. Generation Y and career choice: The impact of retail career perceptions, expectations and entitlement perceptions. Career Development International, 14(6): 570-593.

[27] Ballenstedt, B. and Rosenberg, A. 2008. De-Generation. Government Executive, 4(8): 18-23.

[28] BSG Concours. 2007.Engaging Today's Young Employees. Results Research Project YE. Buahene, Adwoa K and Giselle Kovary. 2003. The Road to Performance Success: Understanding and Managing the Generational Divide. n-gen People Performance Inc.

[29] Blain, A. 2008. The Millennial Tidal Wave: Five Elements That Will Change The Workplace of Tomorrow. Journal of the Quality Assurance Institute. 22(2): 11-13.

[30] Cruz, Cathy S. 2007. Gen Y: How Boomer Babies are Changing the Workplace. Hawaii Business, 52: 11-38.

[31] McLean, G.N. 2006. Organization Development: Principles, Processes, Performance., San Francisco, CA: Berrett-Koehler

[32] Ng, T.W.H., Eby, L.T., Sorensen, K.L. and Feldman, D.C. 2005. Predictors of objective and subjective career success: a meta-analysis. Personnel Psychology, 58: 367-408.

[33] Hall, D.T. 2002. Careers in and out of Organizations, Sage, Thousand Oaks, CA.

[34] Sturges, J., Guest, D., Conway, N. and Davey, K.M. 2002. A longitudinal study of the relationship between career management and organizational commitment among graduates in the first ten years at work. Journal of Organizational Behavior, 23(6): 731-748.
About Author(s):

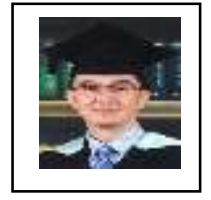

Johnny Ding Dung Ngie, a manager of production engineering. Graduated with a Commonwealth Executive Masters of Business Administration (CeMBA) from Wawasan Open University. He was technician after graduated from Polytechnic Ungku Omar, Malaysia. Thus, his current research interests include personal and contextual characteristics and career satisfaction among engineers in his organization.

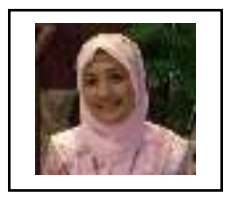

Nasina Mat Desa lives in Penang,

Malaysia and she is a senior lecturer at the School of Distance Education, Universiti Sains Malaysia. She graduated from Universiti Sains Malaysia with a Doctor of Business Administration in 2009 and a Master of Business Administration in 2002. She has worked at several corporate organizations which include AmBank, Manpower Staffing International,

Motorola, and Osram Opto

Semiconductors before becoming a senior lecturer at Universiti Sains Malaysia. Her current research interests include organizational studies (workplace behaviour and leadership) and human resource management. She has published and presented her work locally and internationally.

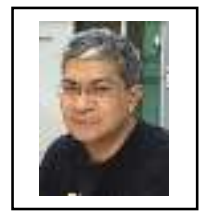

Dr Muhammad Hasmi Abu Hassan Asaari, a senior lecturer at School of Distance Education in Management, specifically in the area of leadership and strategic management. Academically, he holds BSBA (Management), MBA and $\mathrm{PhD}$. He had vast experience in the banking and telecommunication industries, prior to the academia. He also published and presented various articles in journals and conferences. He has been a trainer during the banking and academia. 